\title{
Numbness of Half of the Tongue
}

\author{
R.M. Sadler, T. Curran and W.E.M. Pryse-Phillips
}

\begin{abstract}
We report a case of intermittent compression of the lingual nerve due to sialolithiasis and presenting with episodic unilateral numbness of the tongue. Removal of the obstruction has relieved the patient of symptoms over a 21 month period to date.
\end{abstract}

RÉSUMÉ: Engourdissement de la moitié de la langue Nous rapportons un cas de compression intermittente du nerf lingual due à une lithiase salivaire et se présentant par des épisodes des d'engourdissement unilatéral de la langue. L'exérèse de l'obstruction a laissé le patient asymptômatique depuis au moins 21 mois.

Can. J. Neurol. Sci. 1986; 13:107-108

Numbness of half of the tongue is an unusual complaint with few documented causes. The neck-tongue syndrome, ${ }^{1,2}$ trigeminal sensory neuropathy ${ }^{3}$ and lingual nerve trauma ${ }^{4}$ have been reported as causes while many other conditions lead to numbness in additional areas supplied by the trigeminal nerve. ${ }^{5} \mathrm{We}$ report here the case of a patient with isolated hemilingual numbness due to an uncommon cause.

\section{Case History}

A 36 year old woman presented with an 8-month history of intermittent stereotyped episodes of left-sided tongue numbness. In each, there was an abrupt onset of profound sensory disturbance involving the left anterior-lateral aspect of the tongue (". . . . similar to getting freezing at the dentist"). Each episode lasted 5 - 15 minutes and occurred approximately once every $2-3$ weeks. The attacks were not associated with any perceptible tongue weakness nor other neurologic symptoms. Eventually, the patient noted that with each episode she experienced a sensation of "fullness" in the left submandibular region, with resolution of the swelling and associated transient increase in salivation at the end of the attack. There were no precipitating factors, such as food ingestion or hunger. The past medical history was unremarkable.

The general physical examination, with particular attention to the oral cavity was normal, as was a detailed neurological examination including appropriate testing of the tongue for general sensation and taste.

In hospital, provocative tests using lemon and onion in the mouth failed to reproduce the patient's symptoms and no spontaneous attacks were observed. Soft tissue X-Rays revealed a density in the region of the submandibular gland. A sialogram demonstrated complete obstruction of the left submandibular duct, $3 \mathrm{~cm}$ distal to its origin.

Surgical exploration confirmed the presence of a sialolith in the duct. The adjacent lingual nerve and the hypoglossal nerve were identified and appeared normal. Microscopy of the excised submandibular gland revealed nonspecific chronic inflammatory changes. In the 21 months since operation the patient has been free of symptoms.

\section{Discussion}

This patient presented with the unusual symptom of periodic hemilingual numbness. The stereotyped nature of the attacks, in conjunction with the patient's observations of simultaneous submandibular swelling and transient profuse salivation at the termination of the event, led to the correct diagnosis. Presumably intermittent obstruction of the submandibular duct by the sialolith led to proximal dilatation of the duct and submandibular gland with compression of the lingual nerve. Relief of the obstruction gave complete relief of symptoms.

The afferent supply from the mucous membrane of the tongue is almost entirely through the lingual and glossopharyngeal nerves with the fibers of the lingual nerve distributed to approximately the anterior two-thirds of the tongue while the glossopharyngeal nerve supplies the posterior third. ${ }^{6}$ The course of the lingual nerve, and its anatomical relations are illustrated in Figure 1. In this patient the nerve was presumably compressed as it passed lateral to hyoglossus and medial to the submandibular duct. The nerve carries only fibers subserving general sensation (touch, pressure, pain and temperature), the sensation of taste being carried by the chorda tympani. Variations from the classical anatomical description have been described. ?

The principal feature of obstruction of the submandibular duct is swelling of the gland in association with eating: the swelling subsides completely or partially between meals. The partially-obstructed uninfected gland is usually soft and nontender to palpation. ${ }^{8}$ At some point after the onset of duct obstruction, secondary infection almost always occurs and the gland becomes enlarged, indurated, tender and sometimes purulent ${ }^{8.9}$ In a review of the literature we have been unable to locate any report of a patient with submandibular sialolithiasis 


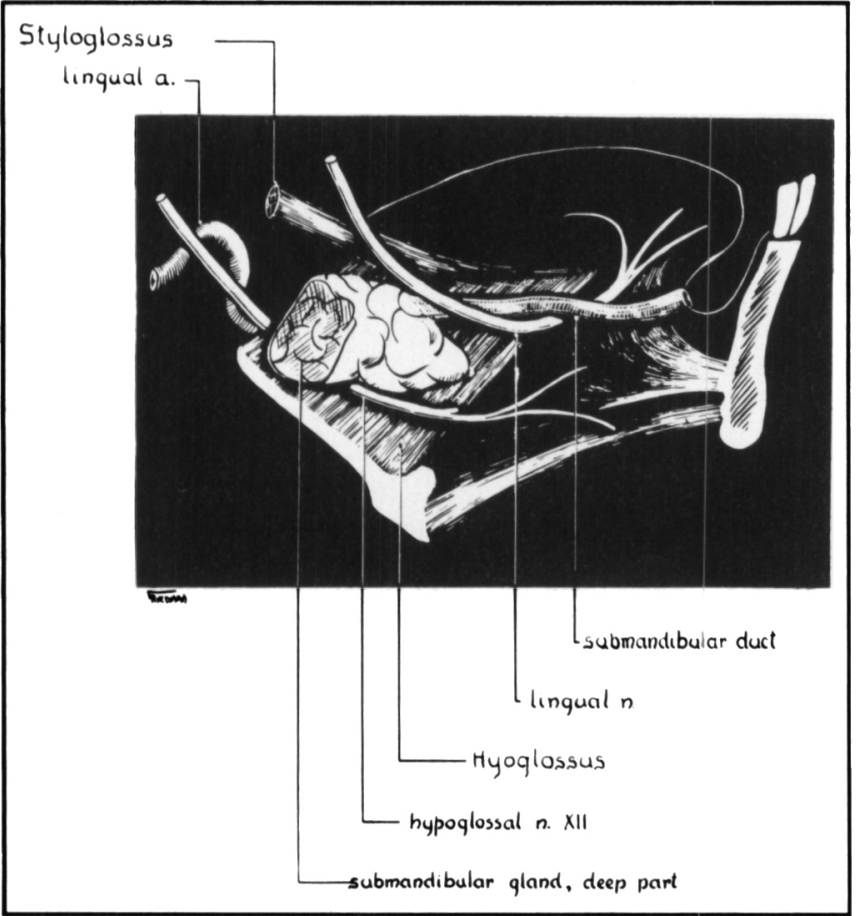

Figure 1-Anatomy of the Right Submandibulargland andadjacent structures. Reproduced with permission, from Friedman SM. Visual anatomy. Vol. I. Head and Neck. Hagerstown, Harper and Row. 1970.

who presented with sensory disturbance of the tongue, although one case ${ }^{4}$ with "chronic sialoadenitis" presented with "intermittent paresthesia, right side of tongue".

Isolated lingual neuropathy, unlike mental neuropathy, ${ }^{10}$ has seldom been described in association with malignancy. Trigeminal sensory neuropathy may involve only the mandibular sensory division but the tongue is not the only area in which numbness is felt. ${ }^{3}$

In the neck-tongue syndrome, head turning is the necessary and adequate precipitant of symptoms due to involvement of afferent fibres from the lingual nerve which pass through the hypoglossal nerve to the $C_{2}$ ventral ramus ${ }^{1,2}$ beside the subluxating $\mathrm{C} 2 / \mathrm{Cl}$ articulatory process. It seems possible that the numerous conditions noted by Horowit $z^{5}$ could present with isolated lingual numbness, but we have discovered no such reports.

The oral surgery and otolaryngologic literature contain abundant descriptions of the typical presentations of submandibular duct stones but do not mention numbness of the tongue. Other reports of isolated lingual numbness have emphasized traumatic (including iatrogenic) and infective causes. ${ }^{4,11.12,13} \mathrm{We}$ suggest, however, that benign lesions may account for the problem, as in the case described here.

\section{REFERENCES}

1. Lance JW, Anthony M. Neck-tongue syndrome on sudden turning of the head. J. Neurol. Neurosurg. Psychiat. 1980; 43: 97-101.

2. Elisevich K, Stratford J, Bray G, Finlayson M. Neck-tongue syndrome: operative management. J. Neurol. Neurosurg. Psychiat. 1984; 47: 407-409.

3. Blau JN, Harris M, Kennett S. Trigeminal sensory neuropathy. N. Engl. J. Med. 1969; 281: 873-876.

4. Moszary PG, Middleton RA. Microsurgical reconstruction of the lingual nerve. J. Oral Maxillofac. Surg. 1984; 42: 415-420.

5. Horowitz SH. Isolated Facial Numbness. Ann. Intern. Med. 1974; 80: $49-53$.

6. Hollinshead WH. The Jaws, Palate and Tongue. In: Anatomy for Surgeons. Vol 1. 3rd. Edit. Hagerstown, Harper and Row. 1982: 325-387.

7. Kiesselbach JE, Chamberlain JG. Clinical and anatomic observations on the relationship of the lingual nerve to the mandibular third molar region. J. Oral Maxillofac. Surg. 1984; 42: 565-567.

8. Hall HD. Diagnosis of diseases of the salivary glands. J. Oral Surgery 1969; 27: 15-25.

9. Cooksey DE. Salivary glands and ducts. In: Textbook of Oral and Maxillofacial Surgery 6th Edit. Ed. Kruger GO. St. Louis, CV Mosby Co. 1984: 672-699.

10. Massey EW, Moore J, Schold SC Jr. Mental neuropathy from systemic cancer. Neurology. 1981; 31: 1277-1281.

11. Greenburg MS. Salivary gland disease. In: Burket's Oral Medicine. 8th Edit. Ed. Lynch MA. Philadelphia, JB Lippincott Co. 1984: 483-500.

12. Goldberg MH, Galbraith DA. Late onset of mandibular and lingual dysesthesia secondary to post-extraction infection. J. Oral. Surg. 1984; 58: 269-271.

13. Loughman $\mathrm{E}$. Lingual nerve injury following tracheal intubation. Anaesth. Intens. Care. 1983; 11: 171. 